ETERNA MARIA...

\author{
Larissa Silva Alves* \\ Adriana Maria de Abreu Barbosa ${ }^{* *}$
}

RESUMO: Objetiva-se aqui apresentar uma análise discursiva da relação teórico-literária do conto "Maria" de Conceição Evaristo com a teoria filosófica de Simone de BEAUVOIR, "A mulher independente". Com base numa perspectiva feminista e com abordagem teórico-metodológica da autora Gloria Jean Watkins, mais conhecida por bell hooks, trataremos aqui de averiguar os pontos comumente marcados pela condição feminina referente à classe social e etnia. Partindo de uma perspectiva abstrata e biológica da composição feminina, discutiremos a relação entre essa composição e a condição social da mulher negra brasileira aos olhos de Maria. Ao tratar-se da integridade feminina, nos apropriamos de conceitos que tragam a relação entre o imaginário discursivo e a composição emocional da mulher negra.

PALAVRAS-CHAVE: Crítica Feminista; Escrevivência; Feminismo negro; Literatura feminina.

\title{
Introdução
}

O feminismo tratado aqui quanto corrente do pensamento que aproxima as mulheres para uma visão humanista e igualitária em relação a diferenças do sexo biológico, é o mesmo feminismo que, no século XXI, têm grande visibilidade política e empodera as mu-

\footnotetext{
* Mestranda em Letras: Cultura, Educação e Linguagens, pela Universidade Estadual do Sudoeste da Bahia.

${ }^{* *}$ Doutora em Semiologia pela Universidade Federal do Rio de Janeiro (UFRJ). Realizou estágio de Pós-doutorado no Programa de Pós-graduação em Letras da Universidade Federal de Pernambuco (UFPE). Professora Titular da Universidade Estadual do Sudoeste da Bahia (Uesb).
} 
lheres em combate ao machismo estrutural. Visando que essas diferenças biológicas molduram papéis estabelecidos socialmente, o gênero é o ponto de partida para compreender a posição de "Maria" mediante os padrões sociais, concernentes a questão da classe social. Esta personagem literária criada por Conceição Evaristo é uma mulher, do sexo feminino, tipicamente brasileira, supõe-se que negra, empregada doméstica e reside na região periférica da sua cidade.

Esse estudo nos leva a compreender a teoria filosófica de Simone de Beauvoir, "A mulher independente" em um comparativo ao conto de Conceição Evaristo, "Maria", na tentativa de apontar os pontos comuns marcados pela condição feminina referente à classe social, à luz de bell hooks. Estudar essa temática abarca reflexões importantes acerca do cotidiano e da realidade da mulher negra brasileira, bem como sua integridade feminina.

A autora do conto "Maria" é uma mulher negra, brasileira e doutora em Literatura Comparada pela Universidade Federal Fluminense. "Ativista dos movimentos de valorização da cultura negra no Brasil, estreou na literatura na década de 1990, quando passou a publicar seus contos e poemas na série Cadernos Negros” (LITERAFRO, 2019). Em meio à trajetória, publicou o livro de contos Olhos d'água em 2014, finalista do Prêmio Jabuti na categoria "Contos e crônicas". Nessa coletânea encontramos o conto "Maria", que nos motivou a desenvolver este estudo.

Simone de Beauvoir, por sua vez, "foi uma escritora francesa, filósofa existencialista, memorialista e feminista, considerada uma das maiores representantes do existencialismo na França" (FRAZÃO, s/d). Nascida em Paris, formada em filosofia pela Universidade de Sorbonne, em 1929 e mais tarde professora de filosofia aos 23 anos de idade na Universidade de Marseille, em 1931. Em sua obra mais polêmica, O segundo sexo, ela procura apresentar a integridade feminina com caráter existencialista.

Para completar a composição analítica, temos a famosa escritora, educadora, feminista e ativista social estadunidense, mais conhecida pelo seu pseudônimo: bell hooks. Com nome de origem Gloria Jean Watkins, nascida em 1952, na cidade de Hopkinsville, Kentucky. 
Autora de vasta obra, incluindo cinco livros infantis, bell hooks investiga de uma perspectiva pós-modernas questões relativas a raça, classe e gênero na pedagogia, na história da sexualidade e do feminismo e na cultura em geral. Aluna de uma escola segregada quando criança e admiradora de Paulo Freire durante vida acadêmica, hooks defende a pluralidade dos feminismos e compreende a prática pedagógica como um lugar fundamentalmente político e de resistência nas lutas antirracista e anticapitalista (BOITEMPO, s/d).

Inicialmente, no capítulo "A mulher independente", Simone de Beauvoir contextualiza a situação da mulher e seus papéis sociais agregados no período histórico da Idade Média, utilizando os termos "cortesã, esposa e vassala" para caracteriza-las e criticar as posições femininas pela sociedade francesa. Papéis estes, que ainda são pertinentes em dias atuais. Para essa crítica nada mais definitivo do que o termo: submissão da mulher, imposto pela cultura patriarcal e que o senso coletivo justifica a condição biológica associada aos hormônios designando a fragilidade (cf.: BEAUVOIR, 2016). como algo propício do feminino. Sobre essa condição de gênero e fragilidade, Bell hooks destaca a história de Sojourner Truth, uma mulher nega e escrava que não tinha medo nem vergonha da sua condição. Ao ser interrogada por um homem branco, por sua coragem e braveza feminina, numa audiência na Conferência Anual do movimento do direito das mulheres de Akron, em 1852, ele disse: "Eu não creio que tu sejas realmente uma mulher.", deixando claro a marca do preconceito expressa pelo "desprezo e desrespeito pela natureza feminina e negra":

Não foi uma mera coincidência Sojourner Truth ter sido autorizada a ir ao palco depois de uma homem branco ter falado contra a idéia de direitos iguais para as mulheres, baseando seu argumento, na noção de que a mulher era demasiado fraca para desempenhar a sua parte do trabalho manual - pois ela era de forma inata fisicamente inferior ao homem. (HOOKS, 1981, p. 115)

O episódio da fala de Sojourner Truth ficou emblemático na necessidade de um feminismo negro para repensar a categoria mulher. $\mathrm{O}$ imaginário de fragilidade não era relacionado a mulheres negras. 
Essa concepção do homem branco, eugenista e europeu, pelo qual a feminista negra relata, é proveniente da concepção presente no imaginário ${ }^{1819}$ coletivo, que se apropria das ciências biológicas para justificar a noção de sexo feminino e do gênero feminino, sob o molde do preconceito estereotipado a respeito da capacidade das mulheres.

Apesar das limitações para discutir a mulher negra, este trabalho acredita que Simone de Beauvoir elucidou performances da integridade feminina juntamente com as condições predefinidas socialmente mostrando-nos, em formato crítico, as possibilidades ilusórias em tentativas de emancipar-se como mulher. Falar sobre a emancipação feminina ou a liberdade da mulher é analisado neste contexto, pela filósofa, sendo abordados por conceitos simultâneos, ou melhor, "sinônimas", definindo o perfil de "A mulher independente". O destaque entre a mulher vassala e sua condição, para a autora, consiste no fato de que "não lhe é permitido fazer o que quer que seja" (BEAUVOIR, p. 503), ou seja, embora tenha conquistado o trabalho e sendo dona dos seus próprios esforços, tornam-se submissa também às forças de trabalho. Pensando assim, creio que tal comparação nos remete a situações cotidianas que ferem e limitam a capacidade de libertação da mulher nos outros quesitos da vida. Para que esses quesitos fossem postos e reivindicados, os movimentos feministas desde a década de 60 no Brasil impulsionaram gatilhos norteadores em prol da emancipação da mulher. Nesta época, a própria Beauvoir já fazia parte das preferências literárias e das estantes burguesas no Rio de Janeiro, propondo um olhar filosófico a cerca da condição feminina desabrochado pela filósofa, na França. Dessa forma, nota-se

\footnotetext{
${ }^{18}$ Em Les stéréotypes, c'est bien. Les imaginaires, c'est mieux (Os estereótipos, muito bem. Os imaginários ainda melhor), traduzido por André Luiz Silva e Rafael Magalhães Angrisano, Patrick Charaudeau (2017, p. 578) conceitua o imaginário como "uma forma de apreensão do mundo que nasce na mecânica das representações sociais, a qual, conforme dito, constrói a significação sobre os objetos do mundo, os fenômenos que se produzem, os seres humanos e seus comportamentos, transformando a realidade em real significante. Ele resulta de um processo de simbolização do mundo de ordem afetivo-racional através da intersubjetividade das relações humanas, e se deposita na memória coletiva."

${ }^{19}$ Esse imaginário ao qual nos referimos corresponde à noção relacional de imaginário e de arquétipo, ainda no texto de Charaudeau (2017, p. 577), que descreve o conceito desenvolvido por Jung "como um conjunto de temas recorrentes que construiria os imaginários pessoais sobre um fundo comum de inconsciente coletivo".
} 
a influência que essa literatura trouxe para o Brasil, a ponto de mobilizar mulheres do centro para as margens e vice-versa, apresentando suas reais existências sociais e femininas.

Entre as facetas da mulher apresentadas neste capítulo, o destaque neste trabalho é apontar o lado emocional da mulher. Quando a autora diz "A mulher que se liberta economicamente do homem nem por isso alcança uma situação moral, social e psicológica idêntica à dele" (BEAUVOIR, 2016, p. 505). esse dito é fatídico se relacionarmos a condição feminina diante os desafios deparados no âmbito social em comparação a conduta hegemônica da presença masculina. Diante essa situação, seria fácil apenas comparar tal superioridade a partir da presença e figura masculina, mas sua transcendência surge antes mesmo da sua inserção no meio material de sociabilidade. A priori, o pertence fálico juntamente com outros aparatos biológicos agrega valores ao universo masculino obstante a figura feminina. Sobre o lado emotivo, podemos destacar uma citação em que a autora justifica:

(...) é ainda muito mais difícil para a mulher do que para o homem estabelecer as relações que deseja com o outro sexo. (...) a mulher vassala não se acha aliás em situação privilegiada: sexual e sentimentalmente, a maioria das esposas e das cortesãs é radicalmente frustrada. Se as dificuldades são mais evidentes na mulher independente é porque ela não escolheu a resignação e sim a luta.

Assim, ao nos basear por esta análise crítica da teoria filosófica de Beauvoir e de bell hooks, partindo de uma perspectiva abstrata e biológica da composição feminina, discutiremos a seguir a relação entre essa composição e a condição social da mulher negra brasileira aos olhos de Maria. Objetiva-se com este trabalho, averiguar os pontos comumente marcados pela condição feminina referente à classe social e etnia.

\section{Discussão teórica}

As abordagens históricas referentes às condições sociais da mulher no Brasil escalam desde a formação das comunidades indígenas até a consolidação da República no Brasil. Essas condições giram em torno de perspectivas culturais que, na transposição de uma 
sociedade simples para sociedades $\operatorname{complexas}^{20}$, estruturam o papel social da mulher a determinadas funções que são correspondentes às suas capacidades biológicas. Os fatores que implicam para determinar essas capacidades estão ligados à formação óssea, as alterações hormonais, entre outros condicionantes que justificam, culturalmente, também, a incapacidade de realizar atividades adversas às suas limitações naturais. Portanto, o desempenho econômico, social e político de determinadas comunidades indígenas, por exemplo, era gerado pela divisão do trabalho de homens e mulheres, cada qual com suas funções estabelecidas. Se tratando aqui da mulher, consequentemente do feminino, os papéis predestinados às mulheres indígenas eram focalizados nas atividades domésticas: cuidados com o lar, educação das proles e preparação dos alimentos. Por esse viés, Maria Amélia de Almeida Teles (1999) traça o perfil condicionante das mulheres que viveram cada período histórico do Brasil.

Apropriando-se das escritas contextualizadas na época escravocrata no Brasil, além de citar a cultura indígena e o papel das mulheres, queremos maximizar a concepção analítica desse trabalho para o lugar da mulher negra, pobre e periférica na sociedade brasileira. Para essa visualização, partiremos da concepção histórica do Movimento das mulheres negras e o feminismo negro analisado pela americana bell hooks. A discussão iniciada acima, sobre o caso de Sojourner Truth, ativista do movimento das mulheres, que subiu ao palco na Conferência para defender a igualdade social para as mulheres, em 1852, é uma referência de feminista para o movimento das feministas negras americanas. Diante um cenário onde apenas homens brancos e mulheres brancas detinham o poder da fala. "O seu ardor em falar em público a favor dos direitos das mulheres não obstante a desaprovação pública, pavimentou a resistência de modo a que outras mulheres negras de pensamento político expressassem as suas visões” (HOOKS, 1981, p. 115). Lembrando que a luta por igualdade

\footnotetext{
${ }^{20}$ Sociedades simples e sociedades complexas são conceituadas, pelos antropólogos, para distinguir certo grau de civilização de uma comunidade a outra, podendo destacar a organização, estrutura, hierarquia de uma sociedade em relação à outra.
} 
social das feministas negras perpassa pelos embates sociais discutidos em pautas sobre racismo $^{21}$ e sexismo ${ }^{22}$. Ainda que as mulheres negras não tivessem o reconhecimento por "ser uma mulher" (como ficou surpreendido o homem branco na conferência), as vozes das mulheres negras como a de Sojourner foram necessárias para que esse cenário se transformasse. Ainda em bell hooks, podemos ver quais pautas eram importantes para as mulheres feministas brancas e as pautas das mulheres negras. O ponto chave dessa discussão e que faz inferência nesse trabalho, dentre outras pautas que merecem destaque, é que a organização das mulheres brancas

podiam confinar e a sua atenção em questões como a educação, a caridade, ou a formação de sociedades literárias, enquanto as negras estavam preocupadas em questões como a pobreza, o cuidar dos idosos e inválidos, ou a prostituição. [...] Muitas mulheres negras jovens que deixavam o Sul e migravam para o Norte eram forçadas a trabalhar como prostitutas. [...] Na troca por transportes e pela garantia de um trabalho à chegada, as mulheres negras assinavam contratos para trabalhar, nos quais elas concordavam em pagar uma comissão equivalente a um ou dois meses de salários. (HOOKS, 1981, p. 119)

A partir dessa distinção, torna-se mais evidente a permanência de pautas como estas aqui no Brasil. Pautas que compatibilizam com as demandas que também foram marcadas pela escravidão. A descrição abaixo, que fora aqui no Brasil, não é diferente do que as mulheres negras americanas passaram durante a escravidão: "As negras que eram favorecidas com a atenção dos seus senhores poderiam aspirar uma vida invejável - a não ser que

21 "O movimento de direitos de mulheres do século XIX podia ter providenciado um fórum para que as mulheres negras exprimissem as suas queixas, mas o racismo das mulheres brancas impediu-se de participarem de forma total do movimento. (...) o racismo tinha de ser eliminado antes de as mulheres negras serem reconhecidas como tendo voz igual às mulheres brancas nos assuntos dos direitos das mulheres.” (HOOKS, 1981, p. 116)

22 "Consiste na discriminação baseada na crença de que homens são superiores às mulheres. Na prática utiliza-se esse conceito para qualificar atos ou palavras com as quais normalmente de forma ofensiva ou vulgar se demonstra o sexismo subjacente à estrutura social." (GARCIA, 2015, p. 18). 
houvesse uma senhora branca que as arruinasse com uma vingança sádica e ciumenta." ${ }^{23}$. Ainda sobre esta comparação, Amelinha Teles completa:

A mulher negra, em sua condição de escrava, transferiu diferentes valores: por um lado, reproduzindo a força de trabalho e, por outro, trabalhando nas tarefas domésticas a serviço dos colonizadores, nas casas dos senhores, nas cidades, no campo.

Sobre estas condições de trabalho, a atuação da mulher brasileira na esfera privada decorre da sua condição e das posições definidas pelo patriarcado. Por essa razão, a atividade doméstica é mais conveniente e satisfatória se desempenhada por uma mulher, de preferência negra e residente em região periférica, onde o fluxo informativo tardam a chegar e as oportunidades de sobrevivência se limitam ao trabalho escravo, caso de Maria. A divisão do trabalho por sexo se consolidou durante o período colonial brasileiro, fortalecendo a tripla opressão da mulher: por sexo, raça e classe. Pensar nessas três condicionantes que limitam a ocupação dos espaços para as mulheres é pensar na importância de problematizar questões sociais a partir do feminismo. Vale ressaltar que o feminismo iniciou a "caráter humanista: busca a libertação das mulheres e dos homens, pois estes têm sido vitimas do mito do macho, que os coloca como falsos depositários do poder, força e inteligência" (TELES, 1999, p. 11). Neste sentido, nascem reivindicações do público feminino sobre as imposições sociais concernentes à dignidade da pessoa humana ${ }^{24}$.

No século passado, o feminismo defendia o conceito de EMANCIPACIONISMO que buscava a igualdade de direitos, mantida na esfera de valores masculinos, implicitamente reconhecidos e aceitos. Hoje, o "feminismo" prescinde da igualdade para afirmar a diferença - compreendida não como desigualdade ou complementaridade, mas como ascensão histórica da própria identidade feminina. (TELES, 1999, p. 10)

\footnotetext{
${ }^{23}$ Em "Breve História do Feminismo no Brasil", Maria Amélia Teles (1999, p. 21) descreve o processo e os papéis das mulheres nos períodos históricos da sociedade brasileira..

${ }^{24}$ É a dignidade que garante uma série de direitos e deveres para esta pessoa, que são fundamentais e obrigatórios, assegurando que a pessoa esteja protegida daquilo que pode ser considerado desumano e degradante. (DIREITOS BRASIL, s/d).
} 
O ponto aqui a ser discutido carece de muita atenção e observação quanto a limitações e a própria essência da pesquisa. Embora estejamos tratando de mulheres, não podemos esquecer-nos de enfatizar e diferenciar quem está produzindo o conto e quem defende a teoria.

Se tratando do lado emocional, que é abstrato, subjetivo e biológico, na descrição por bell hooks, em "Vivendo de amor", temos uma explicação histórica voltada para consequências somáticas desenvolvidas na escravidão ${ }^{25}$. As consequências pela qual ela descreve refere-se ao modo que as mulheres negras eram tratadas pelos seus senhores e pelas dores suportadas, compondo um processo de castigo e opressão dos sentimentos.

Os impactos da escravidão no ato de amar afetaram e transgrediram a forma como os negros e negras expressavam seus sentimentos. "Isso não deveria nos surpreender, já que nossos ancestrais testemunharam seus filhos sendo vendidos; seus amantes, companheiros, amigos apanhando sem razão” (HOOKS, 1994, p. 1). A opressão pela qual sofreram os negros e negras diante situações cruéis como estas, citadas acima, responde os motivos que o fizeram tão ocultos e inibidores de sentimento e solidariedade. As poucas vezes que puderam recompensar gratidão aos que foram solidários a suas angústias e tristezas, como cita a autora, foram castigados pelos seus senhores. Todo esse processo de opressão afetou fortemente as mulheres negras, que por sua vez, eram violentadas e silenciadas diante qualquer demonstração de sentimento. "Elas sabiam, por experiência própria, que na condição de escravas seria difícil experimentar ou manter uma relação de amor” (p. 2). Para esse contexto,

somente em espaços de resistência cultivados com muito cuidado, podiam expressar emoções reprimidas. Então, aprenderam a seguir

25“(...)a vida dos negros é permeada por questões políticas que explicam a interiorização do racismo e de um sentimento de inferioridade. Esses sistemas de dominação são mais eficazes quando alteram nossa habilidade de querer e amar." (HOOKS, 1994, p. 1) 
seus impulsos somente em situações de grande necessidade e esperar por um momento "seguro" quando seria possível expressar seus sentimentos. (HOOKS, 1994, p. 03)

Essa forma de repressão dos sentimentos é expressa por Maria, mulher negra, empregada doméstica, periférica, que carregava uma enorme ferida de um amor resguardado. Amor este que, além de ter sido reprimido, perpassou inconscientemente pelo destinatário em formato de aceitação de Maria e do seu destino.

\section{Eterna Maria...}

Ao passo que as condições da personagem se destacam, notadamente percebe-se que Maria é uma guerreira, moradora de bairro periférico e negra, empregada doméstica. Sim! Três filhos do sexo masculino. No final do expediente, Maria vai para o ponto pegar o coletivo, levando uma gorjeta e algumas frutas que sobraram da festa que a patroa fizera no domingo. Frutas que seus filhos nunca haviam degustado. Ao entrar no coletivo, encontra um homem com traços marcados na sua memória. Ele paga sua passagem e senta ao seu lado nos bancos da frente. Lembrou: era seu primeiro homem, aquele pela qual era perdidamente apaixonada e ainda o sentia em seu corpo. Pai do seu primeiro filho que o abandonara há muitos anos. É interessante notar como a autora destaca o fato de Maria ainda ser apaixonada pelo ex:

\footnotetext{
Maria viu, sem olhar, que era o pai de seu filho. Ele continuava o mesmo. Bonito, grande, o olhar assustado não se fixando em nada e em ninguém. Sentiu uma mágoa imensa. Por que não podia ser de uma outra forma? Por que não podiam ser felizes? (EVA-
} RISTO, 2018, p. 42)

Perceba que, ao olhar da autora, Maria assim como outras mulheres que foram abandonadas e/ou separadas pelos cônjuges guardam um pedacinho do sentimento. Enquanto ele utiliza a comunicação para verbalizar as lembranças e resgatar a chance de tê-la 
mais uma vez, nem que seja apenas para satisfazer os seus caprichos da carne. Aos olhos da teoria destaca-se "Disponível, aberta, é um utensílio, cede facilmente ao feitiço da emoção, está fascinada pelo homem que a colhe como um fruto” (BEAUVOIR, 2016, p. 514) , Maria agora encontra-se "fácil" para o ex-amado, entregue as amarras do antigo amor, como sempre esteve na sua condição de mulher. Carente, encabulada, envolvida, mas pensando em chegar em casa e encontrar seus meninos, oferecer o tal "melão", que nunca tinham experimentado. Em meio às lembranças que passavam em sua memória, Maria imaginava até os planos que fizeram juntos.

Como descreve a filósofa Beauvoir (2016, p. 518), "De um relacionamento que não deu exatamente certo tira o homem quase sempre o benefício do prazer; ela pode muito bem não colher nenhum proveito; mesmo indiferente, ela se presta com polidez ao ato sexual." Diante a realidade de Maria, há uma equivalência com esta citação, no que diz respeito à permanência do sentimento da mulher: enquanto ela fica embebida de sentimentos nostálgicos pelo pai do seu filho, ele relembra mas enfatiza que está sozinho, com intuito de dizer que está carente, sem ninguém, precisando dela, do prazer, do corpo dela, da satisfação sexual que tiveram quando estavam juntos:

Quanto tempo, que saudades! Como era difícil continuar a vida sem ele. (...) Sabe que sinto falta de vocês? Tenho um buraco no peito, tamanha a saudade! Tou sozinho! Não arrumei, não quis mais ninguém. Você já teve outros... outros filhos? (EVARISTO, 2018, p. 42)

A possessão estava ali presente... Ele queria saber se ela continuava sozinha, se o território ainda estivesse sob seu comando, se o "terreno" ainda estava a sua espera. Sim, continuava sozinha, "ficava, apenas de vez em quando, com um ou outro homem” (EVARISTO, 2018, p. 42), com mais dois filhos menores para dar conta. Ainda que não firmasse compromissos com os homens, Beauvoir (2016) credita Maria: 
A mulher que conquista uma independência viril tem o grande privilégio de se relacionar sexualmente com indivíduos, eles próprios autônomos e ativos, que - geralmente - não desempenham em sua vida um papel de parasita, não aprende por sua fraqueza e pela exigência de suas necessidades.

A história se repetiu e, nota-se, que nenhum conseguinte marcou igual a ele. Seguia ali os dois: sentados nas cadeiras da frente do coletivo e ele cochichando. Antes de levantarse, disse "um abraço, um beijo, um carinho no filho" (p. 43). Levantou sacando uma arma e anunciando um assalto. Seu comparsa estava no fundo do ônibus, recolhendo os pertences dos passageiros, do fundo para frente. Maria assustada, sem reação, apática a situação, com medo de levarem sua gorjeta e as frutas dos seus meninos. Sendo a única a não se prejudicar no assalto, não levaram nada seu. Em seguida...

Os assaltantes desceram rápido. Maria olhou saudosa e desesperada para o primeiro. Foi quando uma voz acordou a coragem dos demais. Alguém gritou que aquela puta safada lá da frente conhecia os assaltantes. Maria se assustou. (EVARISTO, 2018, p. 43)

As representações identitárias das mulheres negras, mulatas, morenas, entre outras referências categóricas às mulheres negras, é refletida no imaginário coletivo como um símbolo: objeto da sexualidade, principalmente, as mulatas ${ }^{26}$. Dessa forma, os grupos feministas contemporâneos buscam quebrar com esses imaginários propondo reconstruir novos imaginários, ou seja, propõem uma ressignificação dos imaginários, através das pautas o movimento feminista negro.

Elas (mulheres brancas) diferiam apenas em que as mulheres negras incluíram nos seus esforços de reforma medidas que tinham em vista resolver problemas específicos que elas tinham. Um desses problemas era a tendência geral entre os americanos brancos e entre alguns negros, com lavagem cerebral, em olharem as mulheres negras como

\footnotetext{
${ }^{26}$ A autora feminista negra, Núbia Regina Moreira, descreve a concepção de "mulata" com base na perspectiva de Gilberto Freyre (1992) "Acrescente-se que, aqui, a imagem do símbolo sexual recai sobre a mulata, e não necessariamente nas mulheres negras, o que, de certa maneira, reforça a hierarquia dos papéis sociais apresentados por Freyre, condição que ratifica a representação acerca desse segmento."(p. 20)
} 
sexualmente imorais, promiscuas e luxuriosas - um estereótipo negativo que teve a sua origem na mitologia sexista americana. (HOOKS, 1981, p. 119)

A exemplo: se no imaginário coletivo as mulatas "são boas para transar" e as brancas são "para casar", entende-se que o comportamento sensual (com ou sem intencionalidade) sobrepõe no imaginário coletivo em formato de reafirmação daquilo que já estava formatado no inconsciente coletivo, criando assim um preconceito sobre a presença da mulher negra. Quiçá, seria esse um dos motivos pelo qual Maria permanecia contida no ônibus, calada. Um outro motivo pelo qual fica subentendido é que o término do relacionamento nos dá indícios que a objetificação do seu corpo visada no primeiro encontro pelo seu marcante amor, seria essa projeção imagética da mulher negra que foi considerada por ele. Por esse viés, nesta situação, aponta-se a necessidade dos grupos das feministas negras se posicionarem argumentativamente sobre estes imaginários na tentativa de ressignificálo e aprimorarem a resistência.

Aquela "puta safada" não conhecia os assaltantes, mas sim conhecia o primeiro homem da sua vida, o pai do seu primeiro filho, o homem que marcou a sua primeira experiência e tentativa da formação da sua família. A postura de Maria foi que condenou sua vida dentro daquele ônibus. Talvez o medo, a aflição e o próprio momento nostálgico lhe fizeram uma mulher sem ação. "A primeira voz, a que acordou a coragem de todos, tornou-se um grito: Aquela puta, aquela negra safada estava com os ladrões! (...)Alguém gritou: Lincha! Lincha! Lincha!...” (EVARISTO, 2018). Pobre e eterna Maria... partiu sem deixar um abraço, um beijo e um carinho no seu filho.

A concepção interpretativa de Maria remete a uma mulher negra, categorizada pelo imaginário coletivo e pela própria autora, como mulata, preconceituada e calada pelos passageiros que ali seguiram na condução. Mulher negra, empregada doméstica, nostálgica e idealizadora de um amor romântico sendo linchada pelos seus semelhantes por uma triste realidade social que é reproduzida em um sistema cultural marcado pelo patriarcado eugenista e hegemônico. Em casa, suas crianças lhe esperavam com dessossego para dar um 'boa noite, mãe', mas o que findou foi um 'boa noite, Maria, eterna Maria...'. 
O eterna é remissivo a noção de mais uma alma, mais um corpo negro, de uma mulher negra, que se eterniza nos dados estatísticos como noticiário de homicídio que é justificado socialmente por "me diga com quem andas que te direi quem és". Afinal, a população periférica ao saber da notícia lamenta a morte de Maria com o pesar de “...mas também, estava envolvida com bandidos...”. Cenários de reprodução estrutural do preconceito pela posição da mulher negra na sociedade.

\section{Considerações finais}

Tendo em vista que sendo uma mulher negra, de bairro periférico e de classe de menor poder aquisitivo, Conceição Evaristo pode ser considerada nesse conto como protagonista literária portadora de experiências que, vivenciadas (ou não) por ela, deram sentido à composição das suas escritas feministas ${ }^{27}$.

O uso da literatura quanto meio de comunicação escrita tem como fonte de denuncia pessoal marcados na vida privada e pública com o intuito de alertar e coletivizar experiências que afetaram condições sustentadas pela realidade.

Aos olhos da teoria e sob realidades diferentes, as duas autoras e escritoras se completam, apresentando a real integridade feminina. Uma apresenta uma situação nua e crua, sendo esta próxima da realidade que já vivenciou, a outra teoriza filosoficamente a realidade psicossocial e natural da condição feminina no seio da sua existência. Embora geograficamente distantes e em termos de condições sociais e geracionais diferentes, as duas intelectuais contribuíram positivamente para uma percepção voltada para mulher e sua classe social. Sendo a "mulher", a protagonista do conto e da análise, nota-se que ambas perspecti-

\footnotetext{
${ }^{27}$ Em Escrevivências: identidade, gênero e violência na obra de Conceição Evaristo, o conceito de Escrevivência é expresso por suas próprias palavras dessa forma: "o que levaria determinadas mulheres, nascidas e criadas em ambientes não letrados, e quando muito, semialfabetizados, a romperem com a passividade da leitura e buscarem o movimento da escrita? Talvez, estas mulheres (como eu) tenham percebido que se o ato de ler oferece a apreensão do mundo, o de escrever ultrapassa os limites de uma percepção de vida. [...]” (EVARISTO apud DUARTE; CORTÊS; PEREIRA, 2019 p. 22).
} 
vas refletem sob uma perspectiva feminista. Não apenas por destacar a mulher, mas feminista pela capacidade de denunciar as condições femininas, em determinados contextos. Segundo Carla Cristina Garcia (2015, p. 13), o feminismo é "como a tomada de consciência das mulheres como coletivo humano, da opressão, dominação e exploração de que foram e são objeto por parte do coletivo dos homens no seio do patriarcado sob suas diferentes fases históricas".

Então, notar que dentro do conto e da análise de Simone de Beauvoir existe conscientização sobre a condição feminina é uma forma de constatar que ambos as autoras apresentam perspectivas feministas. O duplo pertencimento de mulher guerreira e mulher apaixonada representadas por Maria são bem definidos por Conceição e Beauvoir, respectivamente.

Maria representa a factual situação da mulher negra brasileira. De modo geral, representa o sensorial feminino diante o papel destinado as mulheres: "boa dona de casa, mãe dedicada, como o são tradicionalmente as esposas. Faz questão de não falhar em seu destino de mulher" (BEAUVOIR, 2016, p. 521). Diante ao fim trágico de Maria, o que a fez encobrir a verdade sobre seu ex-homem e pai do seu filho diante os demais passageiros? Proteção, amor, cuidado correspondentes a sua eterna condição de mulher.

\section{ETERNAL MARY}

ABSTRACT: The objective here is to present a discursive analysis of the theoretical-literary relationship of the short story "Maria” by Conceição Evaristo with Simone de BEAUVOIR's philosophical theory, "The Independent Woman". Based on a feminist perspective and with a theoreticalmethodological approach by author Gloria Jean Watkins, better known as bell hooks, we will try to investigate the points commonly marked by the female condition regarding social class and ethnicity. Starting from an abstract and biological perspective of female composition, we will discuss the relationship between this composition and the social condition of Brazilian black women in the eyes of Maria. When dealing with feminine integrity, we appropriate concepts that bring the relationship between the discursive imaginary and the emotional composition of the black woman.

KEYWORDS: Feminist Criticism; Writing; Black feminism; Female literature. 


\section{REFERÊNCIAS}

BEAUVOIR, Simone de. O segundo sexo: a experiência vivida. Trad. Sérgio Milliet, v. 2, 3. ed., Rio de Janeiro: Nova Fronteira, 2016.

BOITEMPO. Biografia de Bell Hooks. Biografia disponibilizada pela editora Boitempo. Disponível em:<https://www.boitempoeditorial.com.br/autor/bell-hooks-1372> Acesso em: 16 de setembro de 2019 .

$<$ http://direitosbrasil.com/o-que-e-dignidade-da-pessoa-humana/>. Acesso em: 29/11/2017)

CHARAUDEAU, Patrick. Os estereótipos, muito bem. Os imaginários ainda melhor. Trad. André Luiz Silva; Rafael Magalhães Angrisano. Belo Horizonte: CEFET-MG, 2017.

DIREITOS BRASIL. O que é dignidade da pessoa humana? Disponível em: < http://direitosbrasil.com/o-que-e-dignidade-da-pessoa-humana/ >. Acesso em: 29/11/2017.

DUARTE, Constância Lima; CORTÊS, Cristiane; PEREIRA, Maria do Rosário A. (org.). Escrevivências: identidade, gênero e violência na obra de Conceição Evaristo. Belo Horizonte: Idea, 2016.

EVARISTO, Conceição. Olhos d'água. 2. ed., Rio de Janeiro: Pallas Míni, 2018.

FRAZÃO, Dilva. Simone de Beauvoir. Fonte: Disponível em: < https://www.ebiografia.com/simone_de_Beauvoir/> Acesso em: 10 de Março de 2019.

HOOKS, Bell. Não sou en uma mulher. Mulheres negras e feminismo. 1. ed., 1981.

HOOKS, Bell. Vivendo de amor (1994). Disponível em pdf: <www.olibat.com.br > documentos > Vivendo de Amor Bell Hooks>. Acesso em: 17 de setembro de 2019.

GARCIA, Carla Cristina. Breve história do feminismo - São Paulo: Claridade, 2015.

LITERAFRO. Conceição Evaristo. Fonte: Disponível em: <http://www.letras.ufmg.br/literafro/autoras/188-conceicao-evaristo> Acesso em: 07 de Março de 2019.

TELES, M. A. de A. Breve bistória do feminismo no Brasil. São Paulo: Brasiliense, 1999.

Recebido em: 09/10/2019.

Aprovado em: 21/01/2020. 